\title{
Controle de Digitaria horizontalis Pelos Herbicidas Glyphosate, Sulfosate e Glifosate Potássico Submetidos a Diferentes INTERValos de Chuva Após a Aplicação'
}

\author{
Digitaria horizontalis Control by the Herbicides Glyphosate, Sulfosate and Potassium Glifosate \\ Under Different Post-Application Rainfall Intervals
}

JAKELAITIS, A. ${ }^{2}$, FERREIRA, L.R. ${ }^{3}$, SILVA, A.A. ${ }^{3}$ e MIRANDA, G.V. ${ }^{3}$

\begin{abstract}
RESUMO - Avaliou-se a eficiência de sulfosate, glifosate potássico e de diferentes formulações do glyphosate sobre Digitaria horizontalis quando os produtos foram aplicados em condições de pós emergência e as plantas foram submetidas à simulação de chuva de $20 \mathrm{~mm}$ durante 50 minutos, nos intervalos de 1, 2, 4 e 6 horas após aplicação dos herbicidas. O experimento foi conduzido em casa de vegetação, no período de janeiro a abril de 2000, em Viçosa-MG. O delineamento experimental utilizado foi o de blocos casualizados com quatro repetições, sendo os tratamentos dispostos no esquema de parcelas sub-subdivididas. A fitotoxicidade dos herbicidas sobre $D$. horizontalis foi avaliada aos 3, 7, 14, 21 e 28 DAA (dias após aplicação dos herbicidas). Aos 45 DAA, avaliou-se a biomassa seca da rebrota em relação à testemunha sem herbicida. A eficiência do controle cresceu com o aumento do intervalo de tempo entre a aplicação dos herbicidas e a simulação de chuva, para todos os herbicidas. Não se observaram diferenças entre o glifosate potássico, o sulfosate e a formulação do glyphosate denominada Roundup Transorb ${ }^{\circledR}$, para as mesmas condições de aplicação. Estes tratamentos proporcionaram menor capacidade de rebrota das plantas de $D$. horizontalis quando o intervalo sem chuva após a aplicação foi de 4-6 horas. As formulações de glyphosate SL e WG foram mais afetadas pela chuva em todos os intervalos avaliados, quando comparada com os demais tratamentos herbicidas.
\end{abstract}

Palavras-chave: formulações, fitotoxicidade, glyphosate SL, glyphosate WG.

\begin{abstract}
The effectiveness of sulfosate, potassium glyphosate and different glyphosate formulations on Digitaria horizontalis was evaluated when the products were applied in post emergence conditions and the plants were submitted to $20 \mathrm{~mm}$ simulated rainfall during 50 minutes, at intervals of 1,2, 4 and $6 \mathrm{hr}$ after herbicide application. The experiment was carried out under greenhouse conditions from January to April 2000, in Viçosa, Minas Gerais, Brazil, arranged in a split split-plot randomized block design with four replications. The phytotoxic effect of the herbicides on $\boldsymbol{D}$. horizontalis was evaluated at 3, 7, 14, 21 and 28 DAA (days after application). At $45 D A A$, the shoot dry biomass was compared to the control (without herbicide). No differences were observed among potassium glyphosate, sulfosate and glyphosate formulations (Roundup Transorb ${ }^{\circledR}$ ) for similar application conditions. These treatments provided lower regrowth of $\boldsymbol{D}$. horizontalis, when the interval without rain following application was of 4-6 hr. Glyphosate SL and WG formulations were the most affected by rainfall in all the intervals evaluated, when compared to other herbicide treatments.
\end{abstract}

Key words: formulations, phytotoxic, glyphosate SL, glyphosate WG.

1 Recebido para publicação em 12/2/2001 e na forma revisada em 2/7/2001.

2 Pós-graduando, M.S., Dep. de Fitotecnia da Universidade Federal de Viçosa - UFV; ${ }^{3}$ Profs. do Dep. de Fitotecnia da UFV, 36571-000 Viçosa-MG. 


\section{INTRODUÇÃO}

O glyphosate, o glifosate potássico e o sulfosate pertencem ao grupo dos herbicidas inibidores da EPSP sintase e contêm o N(phosphonomethyl) glycina como ingrediente ativo (HRAC, 2001). A diferença entre eles é que o glyphosate é um sal de isopropilamina, o sulfosate é um sal trimetilsulfônico (Hartzler, 1997) e o glifosate potássico é um sal potássico. Estes herbicidas são recomendados para aplicações em pós-emergência, no controle de plantas daninhas perenes e anuais em áreas agrícolas e não-agrícolas, e também em reflorestamentos (Rodrigues \& Almeida, 1998).

Antes de apresentar ação fitotóxica, todo herbicida deve ser absorvido via sistema apoplasto e/ou simplasto e alcançar o seu "sítio" de ação, que se situa geralmente no interior de uma organela (Hess \& Falk, 1990). Entretanto, ao atingir a superfície foliar, parte do herbicida aplicado pode escorrer, ser lavado, volatilizar, secar como um sedimento amorfo, cristalizar após a evaporação do solvente ou, ainda, penetrar na cutícula e permanecer associado a componentes lipídicos desta camada, não sendo translocado. Uma conseqüência imediata é a redução na ação do herbicida no controle das plantas daninhas (Silva et al., 2001).

Em alguns sistemas de manejo, a chuva pode interferir na eficiência dos herbicidas. Uma chuva de baixa intensidade e curta duração pode proporcionar reumedecimento da gota e/ou redistribuição do herbicida na planta, aumentando a eficiência do produto aplicado. No entanto, de modo geral, chuva logo após aplicação de herbicidas reduz sua eficiência no controle das plantas. Isto ocorre geralmente porque parte do produto, ainda não absorvida pela superfície foliar, pode ser lavada (Bryson, 1987; Anderson et al., 1993). Assim, fatores como intervalo de tempo e intensidade e duração da chuva após aplicação dos herbicidas, bem como condições climáticas antes das aplicações, interferem na eficiência dos herbicidas aplicados em pós-emergência (Anderson \& Arnold, 1985).

As diferentes formulações para um mesmo herbicida podem influenciar a velocidade de absorção e de translocação do ingrediente ativo, assim como a eficiência de controle das espécies daninhas (Silva et al., 2001). O período crítico entre aplicação do herbicida em pósemergência e ocorrência de chuva varia com o tipo de formulação, a dose empregada, a solubilidade do produto na água, as espécies de plantas daninhas, as condições de desenvolvimento destas e a quantidade de chuva (Pires, 1998). Portanto, é necessário um "tempo seco", sem chuva após a aplicação, o qual varia conforme cada formulação, para que o princípio ativo seja absorvido e translocado em quantidade suficiente e o herbicida exerça a sua plena atividade. Segundo Pires (1998), nas formulações tradicionais, tanto para o sulfosate (Zapp) como para o glyphosate (Roundup SL), este tempo deve ser de, no mínimo, seis horas para Brachiaria brizantha e as plantas devem estar em plena atividade metabólica.

O objetivo deste trabalho foi avaliar as diferentes formulações do glyphosate (Roundup SL, WG e Transorb), do sulfosate (Zapp) e do glifosate potássico (Zapp QI), quando submetidas à chuva de $20 \mathrm{~mm}$ durante $50 \mathrm{mi}-$ nutos, nos intervalos de 1, 2, 4 e 6 horas após aplicação destes produtos sobre as plantas de Digitaria horizontalis, em de casa de vegetação.

\section{MATERIAL E MÉTODOS}

O experimento foi conduzido em casa de vegetação, no período de janeiro a abril, e o solo utilizado como substrato foi um Podzólico Vermelho-Amarelo Câmbico, fase terraço. Suas características físicas e químicas se encontram na Tabela 1. As sementes de Digitaria horizontalis foram semeadas em bandejas plásticas, sendo as mudas transplantadas para vasos com capacidade de 3,0 L, contendo substrato (solo + fertilizante), quando apresentavam três folhas. Cada vaso recebeu cinco plantas, constituindo uma unidade experimental. A irrigação dos vasos foi feita diariamente, procurando manter o solo próximo a $80 \%$ da capacidade de campo, previamente determinada em condições de laboratório.

Após 30 dias do transplantio, as plantas de Digitaria horizontalis foram cortadas a $5 \mathrm{~cm}$ do solo. Quando a rebrota apresentava aproximadamente $40 \mathrm{~cm}$ de altura, iniciando florescimento, foram aplicados os herbicidas, observando-se as formulações, as doses e os 
intervalos de tempo entre a aplicação e a ocorrência de chuva, conforme a Tabela 2 .

Os herbicidas foram aplicados com pulverizador costal pressurizado com $\mathrm{CO}_{2}$, equipado com barra de dois bicos TT-110.02. Durante as aplicações, manteve-se a pressão constante em 3,0 kgf $\mathrm{cm}^{-2}$, aplicando-se volume de calda equivalente a $200 \mathrm{~L} \mathrm{ha}^{-1}$. As aplicações foram iniciadas às 17 horas, fora da casa de vegetação, com a umidade relativa de $67 \pm 7 \%$ e temperatura de $30 \pm 3{ }^{\circ} \mathrm{C}$ até o final das aplicações. Em seguida, após completado o período sem chuva, os vasos foram transportados para o simulador de chuva, recebendo a precipitação pluviométrica simulada, conforme consta na Tabela 2.

O delineamento utilizado foi o de blocos casualizados, com os tratamentos dispostos no esquema de parcelas subsubdivididas $5 \times 4 \times 5+2$, sendo constituído pelos herbicidas, pelos intervalos de chuva e pelas épocas de avaliação mais as testemunhas (uma sem herbicida e outra com herbicida, ambas não recebendo chuva), com quatro repetições.

A eficiência dos tratamentos no controle de Digitaria horizontalis foi avaliada aos 3, 7, 14, 21 e 28 dias após a aplicação, com base nos sintomas de intoxicação, utilizando a escala de Frans (1979), em que 0\% corresponde à ausência de sintomas visíveis de intoxicação da planta e $100 \%$ à morte total das plantas. Aos 30 DAA, as plantas foram cortadas a $5 \mathrm{~cm}$ do solo, e 15 dias após foi avaliada a rebrota, determinando-se a biomassa seca por vaso. Os resultados foram expressos em porcentagem em relação à testemunha sem herbicida.

Tabela 1 - Características físicas e químicas do solo

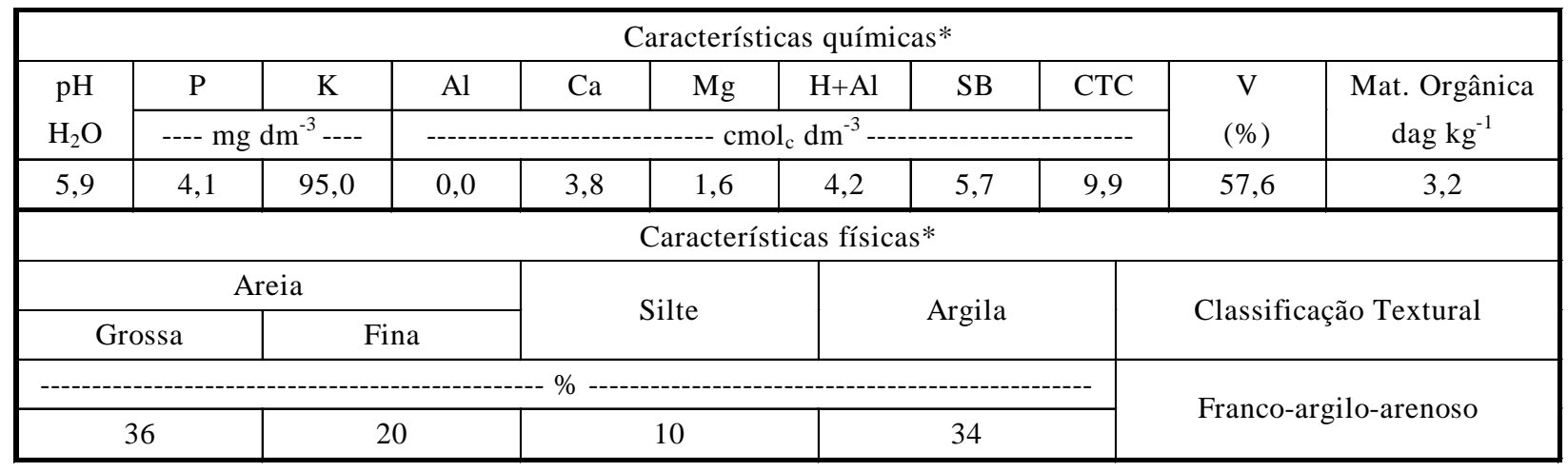

* Análises realizadas nos Laboratórios de Física e Química do Departamento de Solos da UFV.

Tabela 2 - Tratamentos (herbicidas, doses e períodos sem chuva após aplicação das formulações de glyphosate, sulfosate e glifosate potássico) para o controle de Digitaria horizontalis

\begin{tabular}{|c|c|c|c|c|c|c|c|}
\hline \multirow{3}{*}{$\frac{\text { PRODUTOS }}{\text { Roundup SL }(36 \%)^{\frac{1}{}}}$} & \multicolumn{2}{|c|}{ Dose (litro ou kg ha ${ }^{-1}$ ) } & \multirow{2}{*}{\multicolumn{5}{|c|}{ Intervalo de chuva após aplicação* }} \\
\hline & \multirow{2}{*}{$\frac{\text { eq ac. }}{0,72}$} & \multirow{2}{*}{$\frac{\text { p. comercial }}{2,00}$} & & & & & \\
\hline & & & 1 & 2 & 4 & 6 & $\operatorname{sem}^{* *}$ \\
\hline Roundup WG $(72 \%) \stackrel{2}{\prime}$ & 0,72 & 1,00 & 1 & 2 & 4 & 6 & $\operatorname{sem} * *$ \\
\hline Roundup Transorb $(48 \%)^{3 /}$ & 0,72 & 1,50 & 1 & 2 & 4 & 6 & $\mathrm{sem}^{* *}$ \\
\hline Zapp $(33 \%)^{4 /}$ & 0,66 & 2,00 & 1 & 2 & 4 & 6 & $\operatorname{sem} * *$ \\
\hline Zapp QI $(50 \%)^{5}$ & 0,72 & 1,50 & 1 & 2 & 4 & 6 & $\operatorname{sem} * *$ \\
\hline Testemunha sem herbicida ${ }^{6}$ & --- & --- & 1 & 2 & 4 & 6 & $\operatorname{sem} * *$ \\
\hline
\end{tabular}

${ }_{1}^{/}$Formulação comercial contendo $36 \%$ de glyphosate; $2 /$ Formulação comercial contendo $72 \%$ de glyphosate; ${ }^{3 /}$ Formulação comercial contendo $48 \%$ de glyphosate; ${ }^{4 /}$ Formulação comercial contendo $33 \%$ de sulfosate; ${ }^{5 /}$ Formulação contendo $50 \%$ de glifosato potássico.

6/ Testemunha sem herbicida.

* A lâmina de chuva aplicada foi de 20 mm durante 50 minutos; ** Testemunha com herbicida e sem chuva. 
As temperaturas mínima e máxima e a umidade relativa do ar no interior da casa de vegetação, durante o período de condução do experimento, estão apresentadas na Figura 1.

Para interpretação dos resultados de controle observados, procedeu-se à análise de variância dos dados. O efeito do intervalo de tempo sem chuva após aplicação dos herbicidas ao longo das épocas de avaliação foi decomposto em linear, quadrático, raiz quadrada, cúbico, hiperbólico e logístico, obtendo-se em seguida as equações de regressão com maior coeficiente de determinação e que melhor representavam o fenômemo biológico. As estimativas dos parâmetros dos modelos foram testadas pelo teste de t a 1 e $5 \%$ de probabilidade. Para a avaliação dos efeitos dos herbicidas sobre a biomassa seca das plantas, realizou-se a análise de variância, comparando-se as médias por meio do teste de Tukey a 5\% de probabilidade.

\section{RESULTADOS E DISCUSSÃO}

Os resultados da eficiência de controle de Digitaria horizontalis pelas diferentes formulações de glyphosate (Roundup SL, WG e Transorb), sulfosate (Zapp) e glifosate potássico (Zapp QI), em função do intervalo de tempo de chuva após aplicação, podem ser observados nas Figuras 2 a 6.

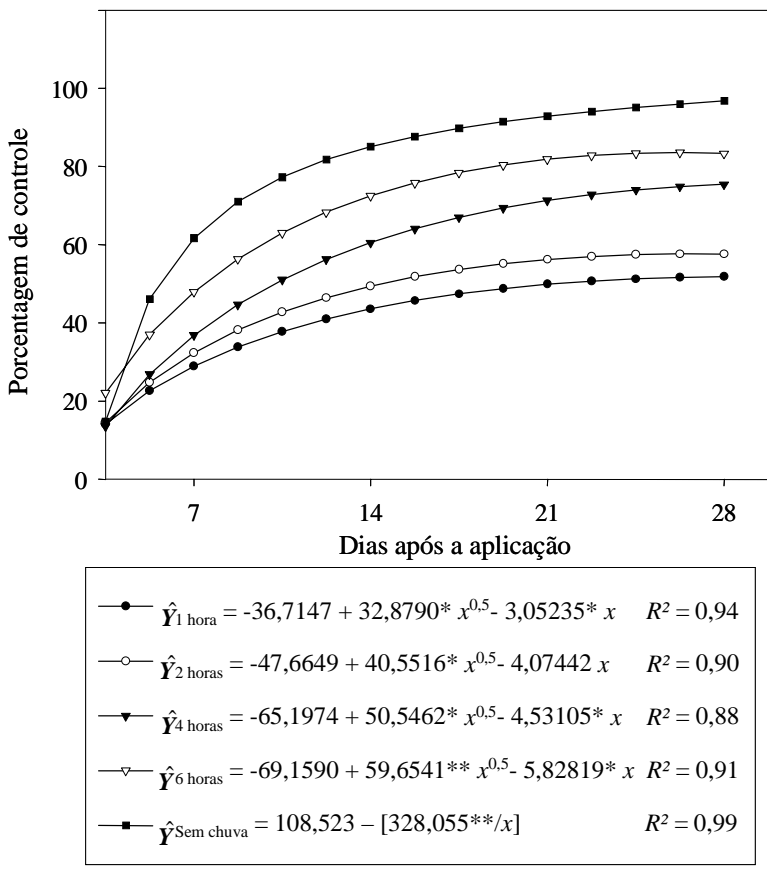

Figura 2 - Porcentagem de controle de Digitaria horizontalis, em função da época de avaliação para os diferentes intervalos de chuva (20 mm em 50 minutos), após a aplicação do Roundup SL.

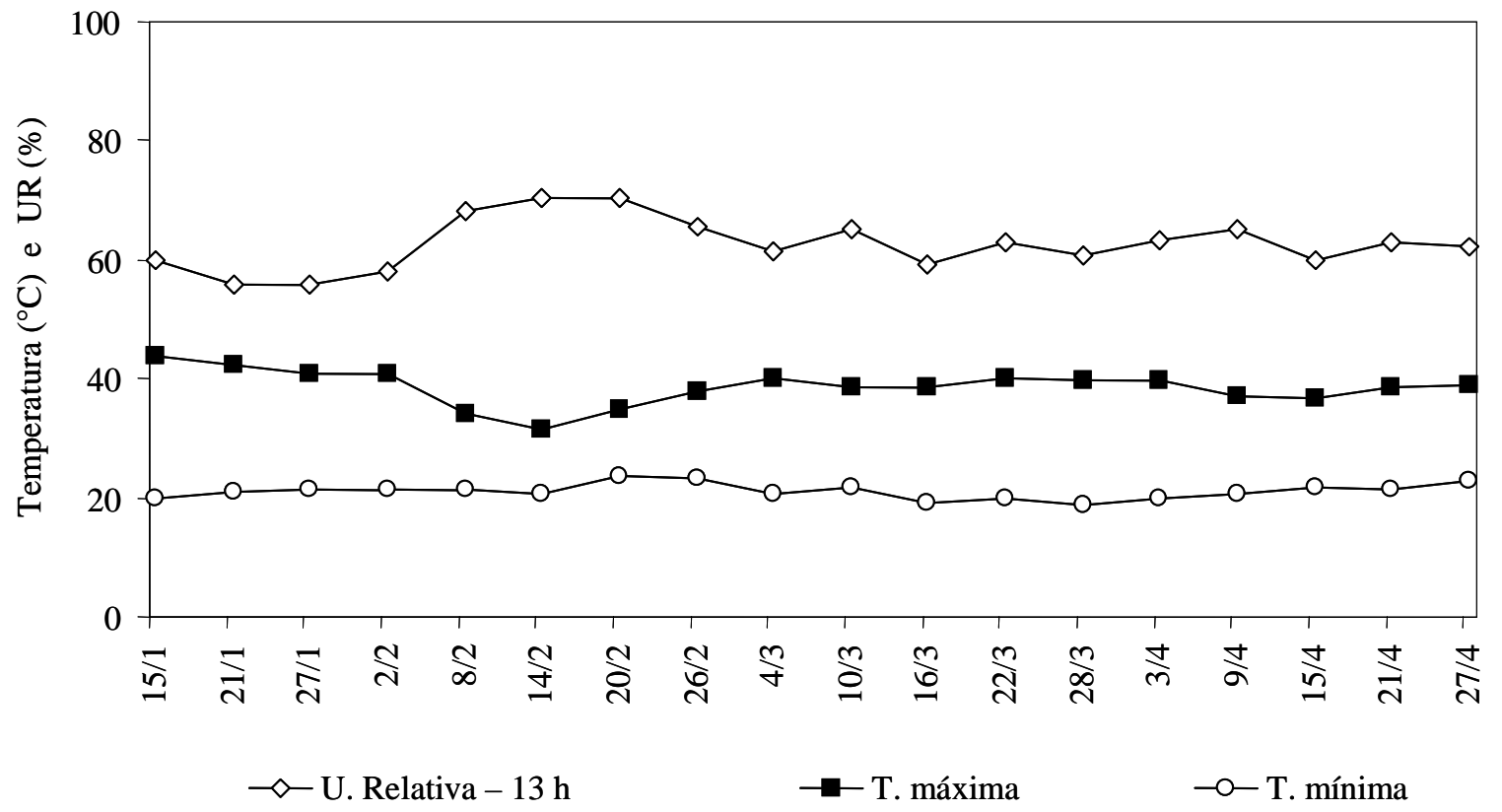

Figura 1 - Dados meteorológicos observados no interior da casa de vegetação, durante o período de condução do experimento. 


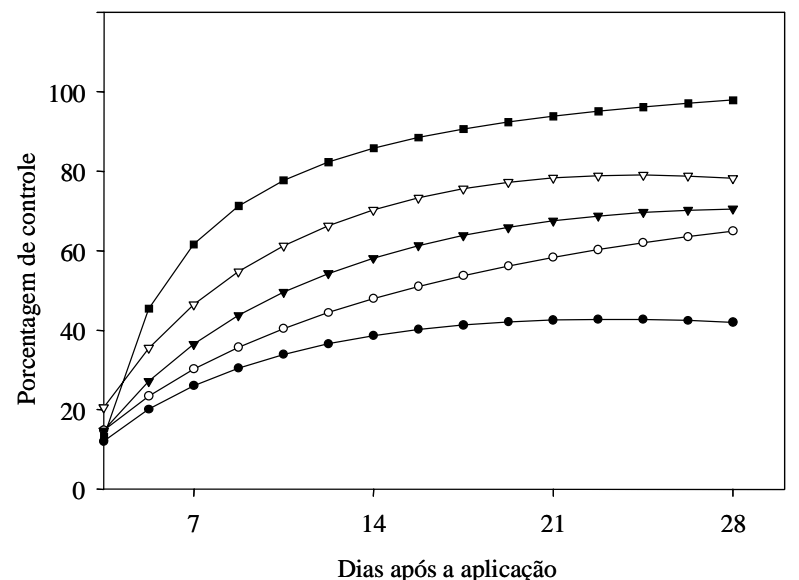

$$
\begin{array}{ll}
\longrightarrow \hat{\boldsymbol{Y}}_{1 \text { hora }}=-39,1232+33,9163^{*} x^{0,5}-3,51176^{\mathrm{ns}} x & R^{2}=0,96 \\
\longrightarrow-\hat{\boldsymbol{Y}}_{2 \text { horas }}=-40,7891+32,6258^{*} x^{0,5}-2,48485^{\mathrm{ns}} x & R^{2}=0,89 \\
\longrightarrow \hat{\boldsymbol{Y}}_{4 \text { horas }}=-59,6421+48,0699^{*} x^{0,5}-4,43413^{*} x & R^{2}=0,93 \\
\longrightarrow \hat{\boldsymbol{Y}}_{\text {6horas }}=-72,8887+61,6429 * * x^{0,5}-6,25219^{*} x & R^{2}=0,91 \\
\longrightarrow \hat{\boldsymbol{Y}}_{\text {Sem chuva }}=109,971-\left[99,5010^{* *} / x\right] & R^{2}=0,99
\end{array}
$$

Figura 3 - Porcentagem de controle de Digitaria horizontalis, em função da época de avaliação para os diferentes intervalos de chuva (20 mm em 50 minutos), após a aplicação do Roundup WG.

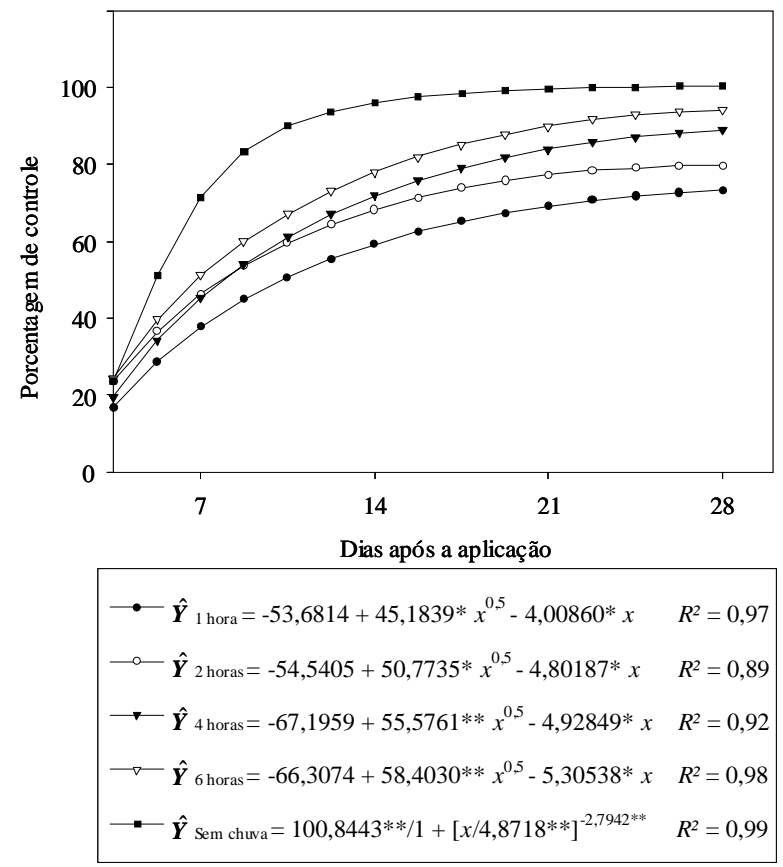

Figura 5 - Porcentagem de controle de Digitaria horizontalis, em função da época de avaliação para os diferentes intervalos de chuva (20 mm em 50 minutos), após a aplicação do Zapp.

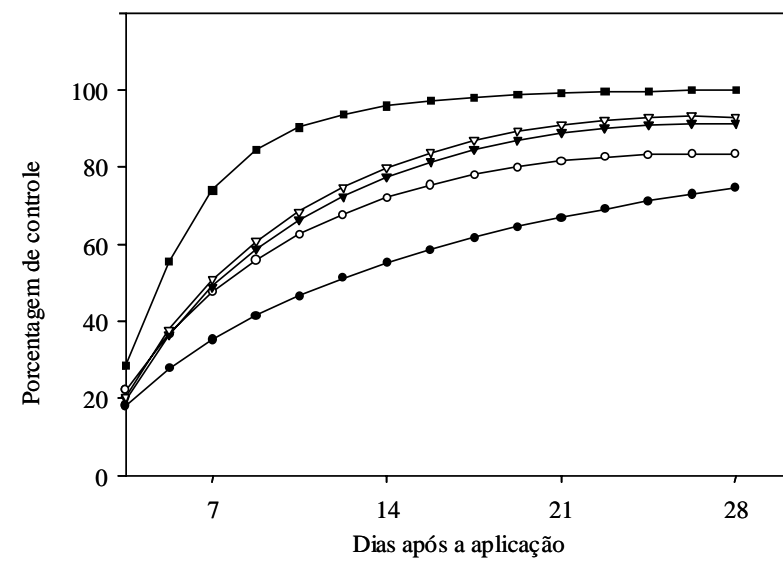

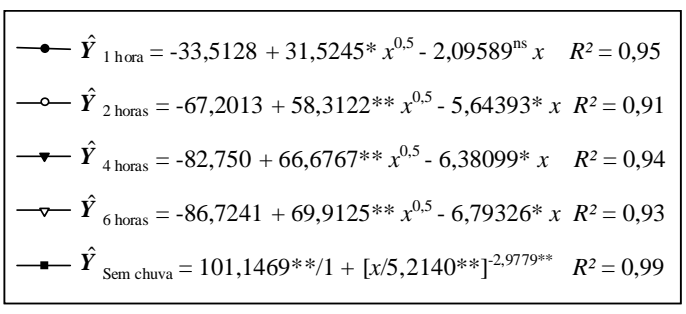

Figura 4 - Porcentagem de controle de Digitaria horizontalis, em função da época de avaliação para os diferentes intervalos de chuva (20 mm em 50 minutos), após a aplicação do Roundup Transorb.

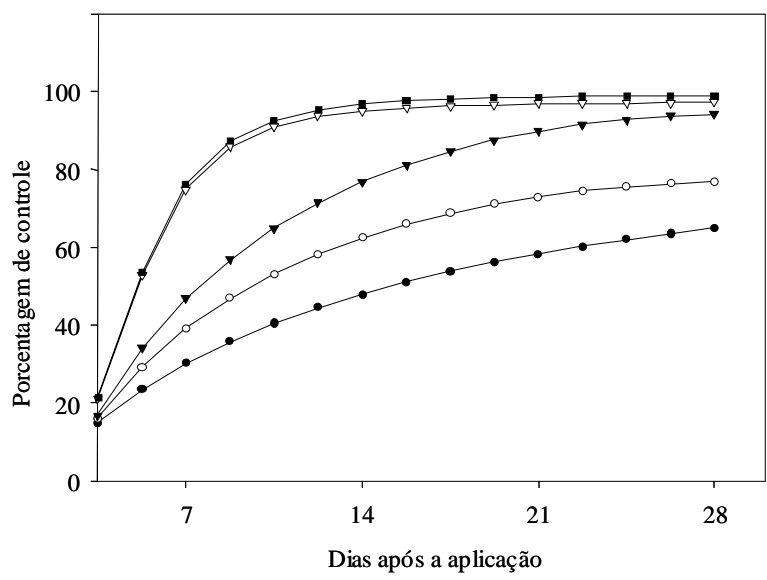

$$
\begin{array}{lll}
\longrightarrow & \hat{\boldsymbol{Y}}_{1 \text { hora }}=-32,0199+28,7392^{\mathrm{ns}} x^{0,5}-1,9695^{\mathrm{ns}} x & R^{2}=0,94 \\
\multimap-\hat{\boldsymbol{Y}}_{2 \text { horas }}=-61,9236+50,1110^{*} x^{0,5}-4,51035^{*} x & R^{2}=0,88 \\
\longrightarrow \hat{\boldsymbol{Y}}_{4 \text { horas }}=-85,8434+66,3233^{*} x^{0,5}-6,10718^{*} x & R^{2}=0,94 \\
\longrightarrow-\hat{\boldsymbol{Y}}_{\text {6horas }}=97,4511^{* *} / 1+\left[x / 5,1569^{* *}\right]^{-4,0988^{* *}} & R^{2}=0,99 \\
\longrightarrow \hat{\boldsymbol{Y}}_{\text {Sem chuva }}=99,1531 * * / 1+\left[x / 5,0172^{* * *}\right]^{-3,6021^{* *}} & R^{2}=0,99
\end{array}
$$

Figura 6 - Porcentagem de controle de Digitaria horizontalis, em função da época de avaliação para os diferentes intervalos de chuva (20 mm em 50 minutos), após a aplicação do Zapp QI.

Planta Daninha, Viçosa-MG, v.19, n.2, p.279-285, 2001 
A ocorrência de chuva logo após a aplicação reduziu a eficiência dos herbicidas. A maior eficiência de controle dos herbicidas sobre as plantas de Digitaria horizontalis foi observada com o aumento do intervalo de tempo entre a aplicação e a ocorrência da chuva. Em todos os intervalos estudados, o Roundup Transorb, o Zapp e o Zapp QI foram mais eficientes no controle da espécie estudada. Quando não houve chuva após aplicação, os resultados se igualaram, com 100\% de controle, aos 28 DAA, para todos os herbicidas, indicando que o tempo de ocorrência de chuva afetou a eficiência de todas as formulações e que não há diferença entre os herbicidas quando o período sem chuva após a aplicação é maior que seis horas. Entretanto, comparando os efeitos dos herbicidas, em cada intervalo de tempo entre a aplicação e a chuva, verificou-se que o Roundup SL e Roundup WG foram menos eficientes e, conseqüentemente, mais lavados que o Roundup Transorb, Zapp e Zapp QI, fato este observado na rebrota das plantas (Figura 7). O período de seis horas sem chuva após a aplicação não foi suficiente para plena atividade do Roundup SL e Roundup WG. Resultados semelhantes foram também observados por Pires (1998).
A rebrota de Digitaria horizontalis aos 45 DAA, para todos os herbicidas nos diferentes intervalos de chuva após aplicação, encontra-se na Figura 7. O Roundup Transorb, o Zapp e o Zapp QI apresentaram excelente controle a partir de quatro horas sem chuva após a aplicação, não diferindo estatisticamente entre si. Para estes herbicidas houve maior absorção e translocação para as regiões meristemáticas da planta, proporcionando 95\% de controle aos 14 DAA (Figuras 4, 5 e 6), tendo como conseqüência menor percentual de rebrota em relação à testemunha sem herbicida em todos os intervalos analisados (Figura 8).

Com base nos resultados observados, verificou-se que na dose de $0,72 \mathrm{~kg} \mathrm{ha}^{-1}$ eq ac. para Roundup SL, Roundup WG, Roundup Transorb e Zapp QI e de 0,66 $\mathrm{kg} \mathrm{ha}^{-1}$ eq ac. para Zapp a ocorrência da chuva uma hora após a aplicação reduziu a eficiência de controle de Digitaria horizontalis, para todas as formulações estudadas, em conseqüência da lavagem do princípio ativo ainda não absorvido pela superfície foliar. As formulações de glyphosate (Roundup SL e WG) foram mais afetadas do que as demais.

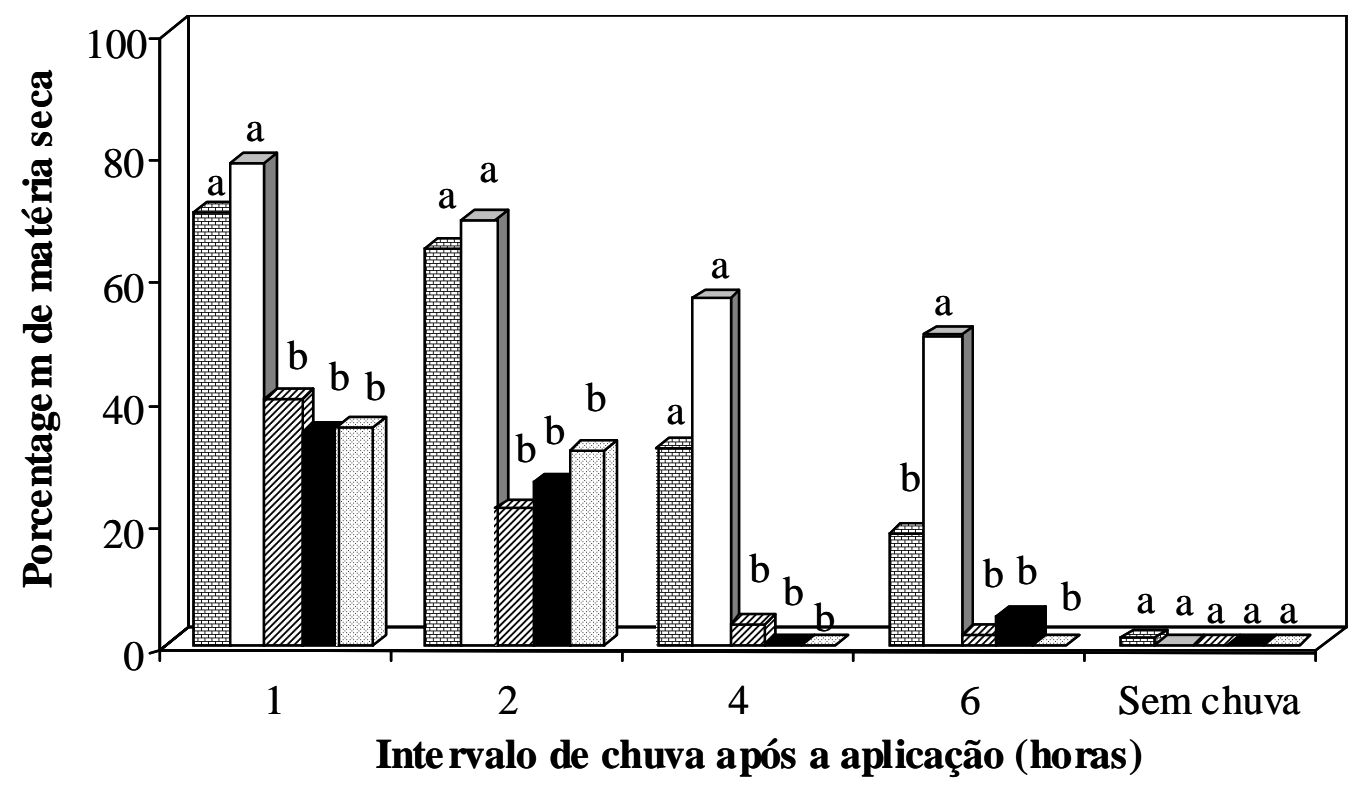

圈 Roundup SL $\quad \square$ Roundup WG $\quad$ Roundup Transorb $\quad$ Zapp $\quad \square$ Zapp QI

Figura 7 - Porcentagem de matéria seca da rebrota de Digitaria horizontalis, em relação à testemunha sem herbicida avaliada aos 45 DAA, em função dos intervalos de chuva (20 mm em 50 minutos), após a aplicação dos herbicidas. Médias dentro de cada intervalo seguidas pela mesma letra não diferem estatisticamente entre si. 

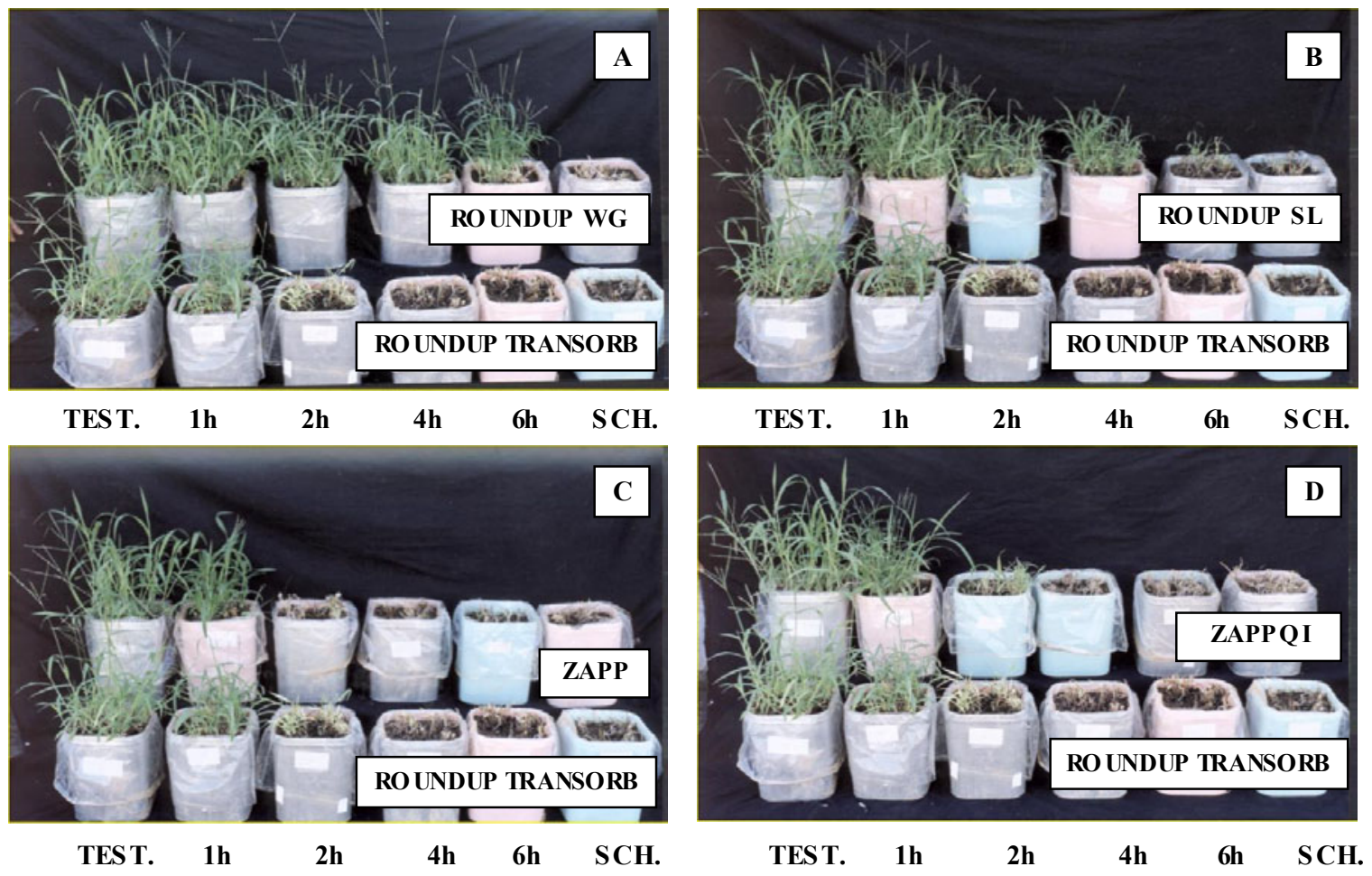

Figura 8 - Rebrota de Digitaria horizontalis, aos 45 DAA, referentes aos herbicidas Roundup WG (A), Roundup SL (B), Zapp (C) e Zapp QI (D), comparados com Roundup Transorb®, em função dos diferentes intervalos de chuva (1, 2, 4 e 6 horas) e das testemunhas sem herbicida e sem chuva (TEST.) e com herbicida e sem chuva (SCH.).

Esta pesquisa avaliou fundamentalmente apenas o efeito dos intervalos de chuva após aplicação dos herbicidas em Digitaria horizontalis. Em decorrência disso, sugerem-se novos trabalhos com a utilização de doses superiores às aplicadas, a fim de que possa propiciar contribuição eficiente em controlar a espéciealvo, dentro de cada intervalo estudado.

\section{LITERATURA CITADA}

ANDERSON, D.M.; ARNOLD, W.E. Rainfall effects on desmediphan and phenmediphan performance. Weed Sci., v.33, p.391-394, 1985.

ANDERSON, D.M.; SWANTON, C.J.; HALL, J.C.; MERSEY, B.G. The influence of soil moisture, simulated rainfall and time of aplication on the efficacy of glufosinate-amonium. Weed Sci., v.33, p.149-160, 1993.

BRYSON, C.T. Effects of rainfall on foliar herbicides applied to seedling johnsongrass. Weed Sci., v.2, p.153-158, 1987.

FRANS, R.E. Measuring plant responses. In: WILKINSON, R.E. (Ed.). Research methods in weed science, Puerto Rico: Southern Weed Science Society, 1972. p.28-41.
HARTZLER, B. Roundup vs Touchdown. 1997 (http:/ / extension.agron.iastate.edu/extweed/ mgmt/qtr1-7/touchdown.htm)

HERBICIDE RESISTANCE ACTION COMMITTEE, 2001 (http://www.plantprotection.org/hrac/ moa2001.htm)

HESS. F.D.; FALK, R.H. Herbicide deposition on the leaf surface. Weed Sci., v.38, p.280-288, 1990 .

PIRES; N.M. Efeitos do glyphosate e do sulfosate após a simulação de chuva em plantas de Brachiaria brizantha submetidas ao estresse hidrico. Viçosa: 1998. 100p. Tese (Doutorado em Fitotecnia) - Universidade Federal de Viçosa, 1998.

RODRIGUES, B.N.; ALMEIDA, F.S. Guia de herbicidas. Londrina, Paraná: Edição dos Autores, 1998. 675p.

SILVA, A.A.; SILVA, J.F.; FERREIRA, F.A.; FERREIRA, L.R.; SILVA, J.F. Controle de Plantas Daninhas, In: ASSOCIAÇÃO BRASILEIRA DE EDUCAÇÃO SUPERIOR - ABEAS. Curso de proteção de plantas. Brasília: 2001. 260p. (Módulo 3 ABEAS.)

Planta Daninha, Viçosa-MG, v.19, n.2, p.279-285, 2001 